\title{
Study of Clinico-Epidemiological Profile and Outcome of Poisonous Snake Bites in Children
}

\author{
Paudel KM'1 , Sharma $\mathrm{S}^{2}$ \\ ${ }^{1}$ Dr. Kiran Mani Paudel, MBBS, MD, Senior Consultant Paediatrician, ${ }^{2}$ Dr. Sindhu Sharma, MBBS, Medical Officer, Department \\ of Paediatrics, Lumbini Zonal Hospital.
}

Address for correspondence: Dr. Kiran Mani Paudel, E-mail: kmp2588@yahoo.com

\begin{abstract}
Introduction: Snake bite poisoning in children is an emergency condition with significant mortality. It is more prevalent in Terai and Inner Terai regions of Nepal especially during monsoon season. There is no study on snake bite poisoning in this part of the country after the introduction of national snake bite management guideline in 2003 . This retrospective study was conducted to evaluate the clinicoepidemiological profile, amount of anti-snake venom used and outcome of snake bites. Materials and Methods: Two hundred and forty six cases of snake bite poisoning admitted in emergency department of the hospital up to the age of 14 years, over a period of 6 years from 2004/2005 to 2009/2010 were evaluated retrospectively. Results: The study showed male predominance (57.3\%) in snake bites with higher incidence of children above ten years of age (58\%). The most of the poisonings $(71.9 \%)$ was seen during June, July and August months which correspond to the monsoon season in Nepal. Majority of the victims had been bitten by unidentified snakes $(52 \%)$, mostly on the fingers \& hands ( $64.6 \%)$. Ptosis was observed in all cases of snake bite poisoning. Slightly less than $1 / 3^{\text {rd }}$ of the children had respiratory distress needing respiratory support. Average ASV used was 18.2 vials. Case fatality rate (CFR) was quite high (28.2\%) with more fatality on those with respiratory distress. Conclusion: As mortality due to snakebite poisoning and consumption of antisnake venom is not reduced by the use of the national protocol 2003, further study to evaluate alternate protocol is recommended.
\end{abstract}

Key words: Case fatality rate, Envenomation, Nepal, Poisoning, Snakebite.

\section{Introduction}

$S_{\text {cales }}^{\text {nald }}$ nake bite is an important medical emergency and cause of hospital admissions in many parts of the South East Asian region ${ }^{1}$ The incidence of bites is high in warm regions, where snakes are abundant and economic activities are mainly agricultural ${ }^{2}$ Among 3,000 known species of snakes, only 200 are poisonous to humans ${ }^{3}$.

It is difficult to be precise about the actual number of morbidity and mortality of snake bites as these events are not systematically reported in most countries and very few countries possess a reliable epidemiological reporting system. It is estimated that the incidence of snake envenomation in the world can exceed 5 millions per year with an associated mortality rate of 125000 persons per year ${ }^{2}$. The highest burden of snake bites exists in South Asia, Southeast Asia, and sub-Saharan Africa ${ }^{4}$. In Asia alone, it has been estimated that four million snakebites occur each year, of which approximately $50 \%$ are envenomed, resulting in 1,00,000 annual deaths ${ }^{2}$.
In Nepal, a total of 77 species of snakes have been reported so far and among them 22 are poisonous. The most commonly found poisonous snakes include 4 species of krait, 3 species of cobra, 9 species of viper, 1 species of coral snake, 1 species of Himalayan pit viper, 1 species of mountain pit viper and 1 species of Russell's viper. The commonest poisonous snakes in the terai and inner-terai regions of Nepal are Cobras and Kraits ${ }^{5}$.

In Nepal, it is estimated that at least 20,000 snake bites occur each year with about 1000 deaths in hospitals, mainly in the Terai region ${ }^{6}$. A community based study ${ }^{7}$ in Nepal showed the annual mortality from snake bite to be 162 per 100000 populations.

Nepal did not have any guidelines for anti-snake venom use in the past. Different doctors and medical persons managed snake bites differently even within the same hospital. The need of protocol was realized by all health workers. Therefore, the protocol for 
the management of snake bites was developed and introduced in Nepal in $2003^{8}$. Based on the few studies done in various parts of Nepal, the case fatality rate of poisonous snake bites ranged from 3 to $58 \%$ before the introduction of the national protocol in $2003^{5,7,9-13}$. Even after the introduction of national protocol the case fatality in children remained high (about 25\%) $)^{14,15}$.

India had introduced a national protocol ${ }^{16}$ for management of snake bites in 2007. This protocol recommended giving anti-snake venom mainly during first three hours. It has been reported that the mortality as well as the consumption of anti-snake venom have decreased after the implementation of this new Indian protocol ${ }^{17}$. Similar guideline was also developed and recommended by World Health Organization for the management of snake bites in Southeast Asia region ${ }^{18}$.

The outcome of snake bites has not been studied in this part of Nepal after the introduction of national protocol. This study was, therefore, conducted to evaluate the clinico-epidemiological profile, amount of anti-snake venom used and outcome of snake bites.

\section{Materials and Methods}

This was a retrospective study conducted on snake bite patients treated at Lumbini Zonal Hospital in Butwal which is a referral hospital of this area with 134 beds and specialist services. The data were collected from the records over 6 years (July/August 2004 to June/July 2010) of patients admitted in emergency ward of the hospital. The patients were managed by the team that comprised of medical officers, physicians, pediatricians and paramedical staffs.

Emergency department is equipped with an electrocardiogram machine, pulse-oximeter, oxygen cylinders, emergency drugs, and resuscitation equipments including endotracheal intubation sets. Anti-snake venom used in this ward is made in India from Haffkine Pharmaceutical Company, Bombay, which is provided by the Ministry of Health and Population, Epidemiology and Disease Control Division and it is available in emergency department throughout the year.

The details of each case were taken from patients' case records. The variables used were most common snake species, gender, the age of victims, the time and site of bite, the symptoms noticed on hospital admission, the treatment instituted, number of ASV used, and the final outcome. The data were entered in a computer database and analyzed using excel.

The diagnosis of snake-bite was established on the basis of a history of snake-bite with examination of the killed snake when available, recognition of the snakes by patients and bystanders and clinical manifestations.

Snake bite victims were observed in emergency department and those who didn't develop signs of envenomation after 8 hours of bite were discharged. Patients were examined with particular attention to their vital signs and evidence of neurotoxicity like ptosis, external ophthalmoplegia, respiratory paralysis and any signs of hemotoxic poisoning.

Envenomed patients were treated according to national guidelines recommended by Epidemiology and Disease Control Division (EDCD) in 2003. Two vials of polyvalent anti-snake venom (ASV) serum were given bolus followed by intravenous infusion of 4 vials 4 to 6 hourly to patients with signs of envenomation. Intravenous fluids and other medicines including antibiotics were also given to children on body weight basis. Patients were closely observed for evidence of early antivenom reactions and managed accordingly. Endotracheal intubation was performed as soon as patients showed signs of respiratory paralysis, and ventilation was assisted. As intensive care unit (ICU) with mechanical ventilators were not available in hospital, intubated patients were managed with bag and mask ventilation by patients' relatives in emergency department. Few cases were referred to other centre. After clinical improvement patients were extubated and were shifted to wards and antivenom was gradually tapered and stopped. Patients were discharged after ophthalmoplegia, ptosis completely subsided and clinically stable.

\section{Results}

Total snake bite cases recorded at Lumbini Zonal Hospital during the study period were 6520, out of which 889 (13.6\%) developed signs and symptoms of envenomation. Among the poisonous bites children (up to 14 years) comprised 246 ( $27.7 \%$.) cases. Male children predominated female children in this study $(57.3 \%$ vs. $42.7 \%$ ). The most affected age group in children was 10 yrs or more followed by 5-9 year age group as shown in figure 1.

Majority of snakes responsible for bites in the study were unknown (52.0\%) followed by Krait as shown in figure 2 .

It is seen in the figure 3 that about $2 / 3^{\text {rd }}(64.6 \%)$ of the bites occurred in hand and fingers and only in a few cases $(5.7 \%)$ the bite sites remained unknown.

It is shown in the figure 4 that most of the poisonous cases occurred in the monsoon season. 
Table 1: Clinical presentations of cases $(n=241)$

\begin{tabular}{|l|c|c|}
\hline Signs \& symptoms* & No of cases & Percentage \\
\hline Ptosis & 241 & 100.0 \\
\hline Respiratory distress & 69 & 28.6 \\
\hline Dysphagia & 48 & 19.9 \\
\hline Pain abdomen & 24 & 9.9 \\
\hline
\end{tabular}

* Cases had one or more signs or symptoms

As shown in table 1 all cases had ptosis as a sign of poisoning and only a few cases had difficulty in feeding. No vasculotoxic cases were found in case records.

As shown in Figure 5 most of the cases were managed with less than 20 vials of antisnake venom.

The number of ASV used ranged from 4 to 90 vials with the average of 18.2 vials. Interestingly, one child who needed 90 vials survived. Five cases were already dead when brought to hospital.

As seen in the Table 2, the case fatality rate among children is more than double that of adult and contributed almost half of the case fatality due to snake bites. Few referred cases were recorded survived.

Most of the bites (around 68\%) occurred during the period of $10 \mathrm{pm}$ to $10 \mathrm{am}$. Likewise, most of the cases (75\%) were brought to hospital within 4 hours of bites.

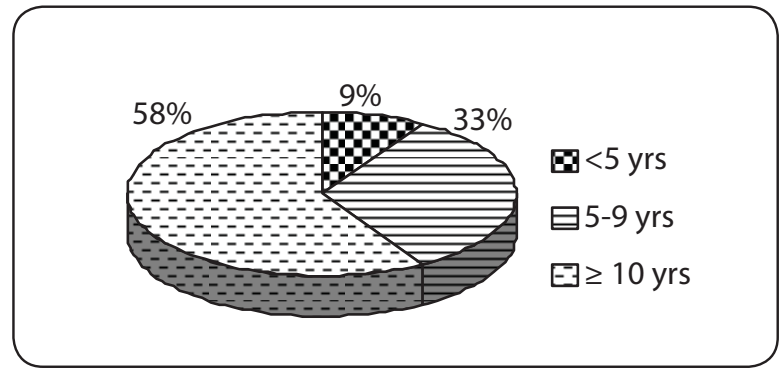

Fig 1: Age distribution of children with poisonous snake bites $(n=246)$

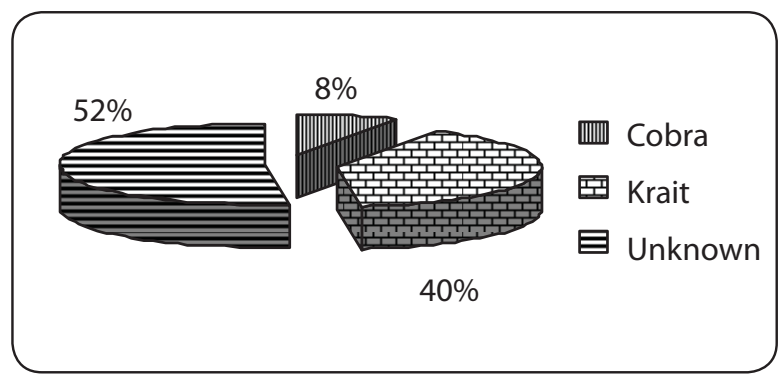

Fig 2: Types of Snakes $(n=246)$

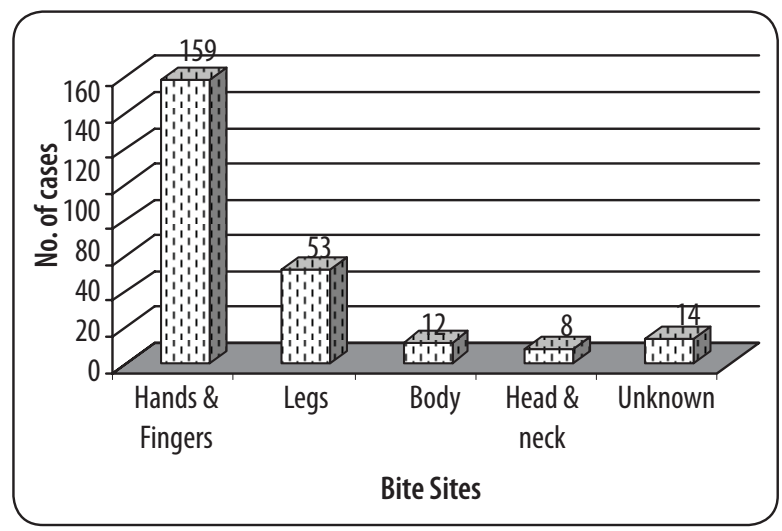

Fig 3: Bite sites of patients $(n=246)$

Table 2: Case fatality in children and adults

\begin{tabular}{|c|c|c|c|c|c|}
\hline Age group & $\begin{array}{c}\text { No. of poisonous } \\
\text { bites }\end{array}$ & No. of deaths & $\begin{array}{c}\text { Case fatality rate } \\
\text { (\%) }\end{array}$ & $\begin{array}{c}\text { Total case } \\
\text { Fatality rate (\%) }\end{array}$ & $\begin{array}{c}\text { Childhood case } \\
\text { fatality (of total) }\end{array}$ \\
\cline { 1 - 4 } $1-14 \mathrm{yrs}$ & 246 & 68 & 28.2 & \multirow{2}{*}{15.9} & \multirow{2}{*}{47.9} \\
\hline$>14 \mathrm{yrs}$ & 643 & 74 & 11.5 & & \\
\hline Total & $\mathbf{8 8 9}$ & $\mathbf{1 4 2}$ & & & \\
\hline
\end{tabular}

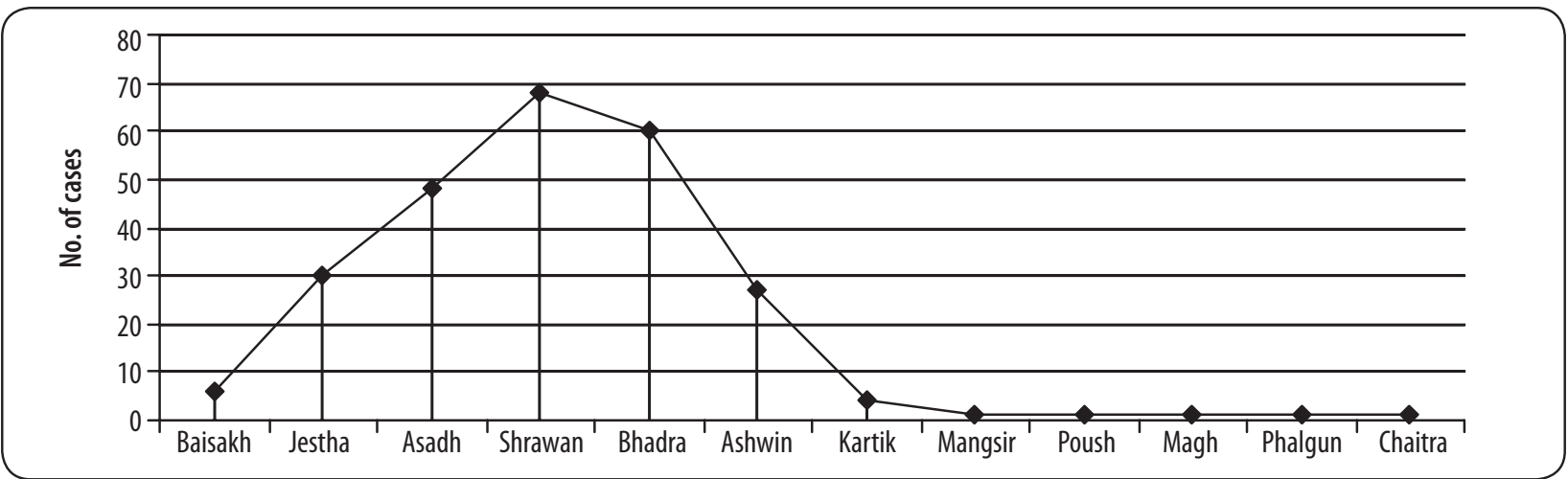

Fig 4: Monthly distribution of cases $(n=246)$ 


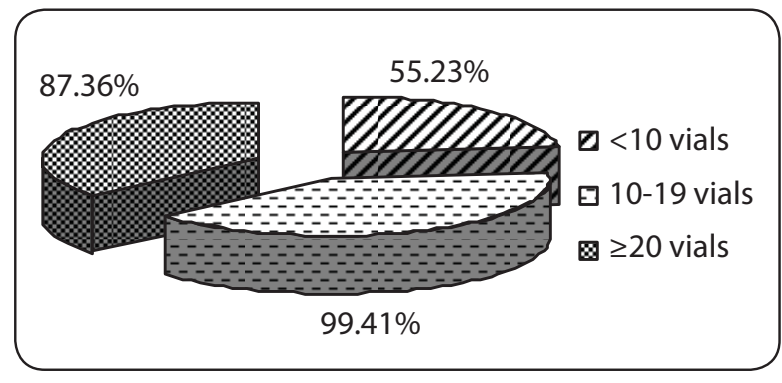

Fig 5: Number of ASV vials used in the treatment $(n=241)$

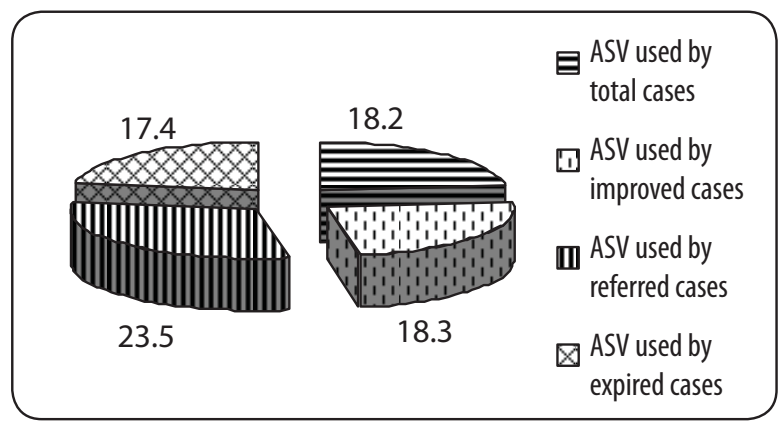

Fig 6: No. of ASV used and outcome of cases

\section{Discussion}

Present study showed that most of the bites occurred in older children. This is in agreement with other studies ${ }^{12,19}$. This could be due to the fact that older children in our part of the world, especially in the communities have to carry out outdoor activities like firewood-collecting, grass-cutting, and looking after the cattle in the fields and field-working exposing them to snakebites.

Male predominance observed in this study is comparable with the previous studies ${ }^{12,13,19-21}$. This observation could be due to male children playing and working outside with sleeveless shirts more frequently than their female counterparts.

In this study, the highest incidence of snakebite poisoning was seen during the months of June, July and August which corresponds to the monsoon season in Nepal. This is also a hot season and the snakes come out of their shelter due to increased humidity and temperature. This seasonal pattern of poisoning was seen in other studies as well9,14,15,21.

The majority of children in this study could not identify the biting snakes. This is possibly because of poor knowledge of children about snakes, poor visibility and bite during night. This finding contrasts with other study where $61 \%$ victims had identified snakes with $58 \%$ being cobra ${ }^{7}$. This could be due to inclusion of adult cases in the study.
Biting sites were the fingers and hands in about $2 / 3^{\text {rd }}$ of the cases in our study. This finding is comparable to previous studies ${ }^{12,21}$. This is possible because the curious young children, while playing, put their fingers and hands into the blind holes or pits where the poisonous snakes can hide in. Similarly the older children may touch the snakes while cutting the grass. In the contrary, some of the earlier studies found lower extremities to be the most frequently bitten sites ${ }^{9}, 10,18,20$. The explanation given by the authors was that the snakes had been accidentally stamped while walking.

The commonest clinical finding in the present study was ptosis which is comparable to previous study ${ }^{12}$. Ptosis is easily noticeable sign both by the guardians and the health workers. Respiratory distress was observed in approximately $1 / 3^{\text {rd }}$ of children and a large majority of them needed respiratory support and had poor outcome. Most of the children (80.2\%) who needed respiratory support died. Respiratory distress occurs mostly as a result of paralysis of muscles of respiration by the neurotoxin and develops only after ptosis has developed. When the treatment of the poisoning is either too much delayed or inadequate after ptosis has been observed, possibility of developing respiratory distress is increased leading to increased mortality.

In the present study, majority of victims (64\%) needed less than 20 vials of ASV during treatment. Only one third of the victims (36\%) needed more than 20 vials. The average number of vials of ASV used during treatment was 18.2 per case. This is comparable to another study where the number of vials used was 19.6 per case ${ }^{20}$. But it contrasts with the previous study in the same centre with lower average consumption of ASVS (14.4 vials per case) $)^{12}$.

Case fatality rate (CFR) was quite high (28.2\%) in this study. This finding is in agreement with earlier studies $^{12,14,15}$. The total case fatality rate in different studies before the introduction of protocol ranged from 3 to $58 \%$. The total case fatality rate observed in this study $(15.9 \%)$ also falls in this range. The case fatality rate in children was found to be more than double of the adult case fatality rate $(28.2 \%$ vs. $11.5 \%)$ and fatality in children constituted $47.8 \%$ of the total fatality. This high CFR in this study is because of the fact that children are at greater risk of severe envenomation due to their smaller size or volume for venom distribution ${ }^{3}$. Secondly, in this study, only the poisonous snakebite cases have been included.

Venom from the Elapids is neurotoxic as it blocks the transmission of nerve impulse from the neuromuscular junction ${ }^{3}$. Venoms should be neutralised as early as possible before they are fixed to neuromuscular junction 
causing respiratory paralysis. Antivenom is most effective if delivered within 4 hours of the bite and is of little value if administration is delayed beyond 12 hours $^{3}$.

In India, in 2007, a new national protocol ${ }^{16}$ was developed with the concept of aggressive use of antisnake venom within 3 hours of the development of first sign of envenomation, ptosis. It is argued that the use of ASV after the development of respiratory paralysis is not beneficial. The use of new protocol resulted in a $66 \%$ decline in the amount of ASV administered to victims and the case fatality rate were found to be decreased by $24 \%{ }^{17}$.

Cases with neurotoxic poisoning with respiratory paralysis need respiratory support in intensive care unit (ICU) set up. As ICU set up was not present in this hospital and intubated patients were bagged by patient parties themselves, the ventilation techniques could be not perfect. This might have lead to more mortality in present setting as most of the fatality was amongst intubated victims with respiratory paralysis.

Although this was a retrospective hospital based study, this descriptive study is hoped to yield epidemiological statistics and information on clinical manifestations and hospital management of the snake bite cases and serve to generate hypotheses for future studies.

\section{Conclusion}

Majority of snake bite poisoning in this region is neurotoxic which may cause respiratory paralysis and may need ventilatory support. So, management of cases in ICU set up is recommended. Neither the use of number of ASV doses nor the case fatality rate decreased with the use of national protocol 2003. Further study is recommended in this part of the country to evaluate the protocol introduced in India with aggressive ASV use within first few hours of envenomation.

\section{Conflict of Interest: None}

Funding: None

Permission from IRB: Permission taken from Medical Superintendent of the Hospital

\section{Acknowledgment}

I would like to thank Medical Superintendent for allowing me to review the record files. I am thankful to medical record officer Laxmi Raj Regmi for his help in data review and Mr. Ram Bahadur Malla for his secretarial help.

\section{References}

1. Warrell DA. WHO/SEARO Guidelines for the clinical management of snake bites in the southeast Asian region. South East Asian J Trop Med Publ HIth 1999; 30:1- 83

2. Chippaux JP. Snake-bites: appraisal of the global situation. Bull WHO 1998; 76 (5):515-24

3. Holve S. Envenomations: In Behrman RE, Kliegman RM, Jenson HB and Stanton BF. Nelson Textbook of Pediatrics. 18th ed. Philadelphia: W.B. Saunders Company; 2007: 2932-35.

4. Kasturiratne A, Wickremasinghe AR, de Silva $N$, Gunawardena NK, Pathmeswaran A et al. The global burden of snakebite: a literature analysis and modelling based on regional estimates of envenoming and deaths. PloS Med 2008;5(11):218.

5. Epidemiology and Disease Control Division, Ministry of Health, Gov of Nepal. Annual Report on Incidence of poisonous snakebite in Nepal. 2001:63-71.

6. WHO. Zoonotic Disease Control: Baseline Epidemiology Study on Snakebite, Treatment and Management in Nepal. WHO Weekly Epidemiol Rev $1987 ; 42: 319-20$

7. Sharma SK, Chappuis F, Jha N, Bovier PA, Loutan L, Koirala S. Impact of snake bites and determinants of fatal outcomes in southeastern Nepal. Am J Trop Med Hyg 2004;71(2):234-8.

8. Shah KB, Shrestha JM, and Thapa CL. Department of Health Services Epidemiology and Disease Control Division, Zoonoses Control Sub-Section. Snakebite Management Guideline. 2003: 1-53.

9. Hansdak SG, Lallar KS, Pokharel P, Shyangwa P, Karki P, Koirala SA. Clinico-epidemiological study of snakebite in Nepal. Trop Doctr 2004;34(1):20-2.

10. Pandey DP, Thapa CL, Hamal PK. Impact of First Aid Training in Management of Snake Bite Victims in Madi Valley. J Nepal Health Res Council 2010;8(16):59.

11. Heap BJ, Cowan GO. The epidemiology of snakebite presenting to British Military Hospital, Dharan, during 1989. J Army Med Corps 1991;137:123-25.

12. Shrestha BM. Snakebite poisoning in children. J Nepal Med Assoc 2002;41:463-67.

13. Sharma SK, Khanal B, Pokhrel P, Khan A, Koirala S. Snakebite-reappraisal of the situation in eastern Nepal. Toxicon. 2003;41:285-89. 
14. Joshi DD. An Epidemiological Study of Snake Bite Cases in Children of Nepal. J Nep Paedtr Soc 2010;30(3):135-40.

15. Pandey DP. Epidemiology of Snake Bites Based on Hospital Survey in Chitwan and Nawalparasi Districts, Nepal. J Nep Health Res Counc 2006;4:51-57.

16. Simpson ID. The pediatric management of snakebite: the national protocol. Indian Pediatr 2007;44(3):1736.

17. Ghosh S, Maisnam I, Murmu BK, Mitra PK, Roy A, Simpson ID. A Locally Developed Snakebite Management Protocol Significantly Reduces Overall Anti Snake Venom Utilization in West Bengal, India. Wilderness Environmen Med 2008;19:267-74.
18. Warrell DA. WHO/SEARO Guidelines for the clinical management of snake bites in the Southeast Asian region. 2010.

19. Kulkarni ML, Anees S. Snake venom poisoning: experience with 633 cases. Indian Pediatr 1994;31:1239-43.

20. Devkota UN, Steinman JP, Kathayat JB. Epidemiology of snakebite; A study from Choharwa Army Camp, Siraha, Nepal. J Nepal Med Assoc 2001;40:57-62.

21. Devkota UN; Steinmann JP; Shah LN. Snakebite in Nepal: a study from Siraha district. J Nepal Med Assoc 2000;39:203-09.

\section{How to cite this article?}

Paudel KM, Sharma S. Study of Clinico-Epidemiological Profile and Outcome of Poisonous Snake Bites in Children. J Nepal Paediatr Soc 2012;32(1):47-52. 